\title{
Research on the Acquirement Approach of
}

\section{Enterprise Competitiveness Based on the Network View}

\author{
Shuzhen Chu \\ Economics and Management School, Nanjing University of Science and Technology \\ Nanjing 210094, China \\ School of International Pharmaceutical Business, China Pharmaceutical University \\ Nanjing 211198, China \\ Zhijun Han \\ Economics and Management School, Nanjing University of Science and Technology \\ Nanjing 210094, China \\ Tel: 86-135-1253-5022Ｅ-mail: csz77844@163.com,csz@cpu.edu.cn
}

\begin{abstract}
Under the market situation of economic globalization, the premise of enterprise existence and development is to foster the competitiveness of enterprise. Starting from the network view, this article will confirm the interest relatives of enterprise and systematically discuss the approach of enterprise competitiveness through such aspects as the formation of enterprise competitive potential, the increase of enterprise competitiveness and the continual renovation of competitiveness.
\end{abstract}

Keywords: Network, Interest relative, Competitiveness, Approach

The western corporate network theory thinks that the enterprise is not opposite with the market, and their relation is mutually connected and osmotic, and the technology needed by the enterprise is acquired through the cooperation and development of the enterprise and exterior institutions to large extents. Since China joined WTO, China enterprises would enter into increasingly drastic international competition. Under this situation, the independent and close traditional enterprise innovation mode has not adapted the requirement of present global competition, and enterprises need to integrate exterior resources through innovation network to enhance innovation ability of enterprise and remedy the deficiency of innovation resources.

\section{Analysis of enterprise interest relatives in the network}

The network is the sum of various relationships happened and established when various principal parts of activities change and transmit resources. These relationships may be informal relationships based on corporate social and cultural backgrounds and mutual trusts, and may be normal relationships happened in the creation process of market trading, knowledge and technology (Gai, 2002, p.47-118). The network is composed by principal part, resource and activity. The principal part of activity in the network includes enterprises, colleges, research institutions, local governments, financial institutions and agencies. Resources include hardware basic establishments, financial capital, human resources. Activities mainly mean the reciprocity among principal parts of activity in the interior of the network (Lei, 2004, p.60-63).

In the network, enterprise is the most important economic unit, and the most direct economical part to create values and actualize increment of value. According to the activity situation among principal parts and in interiors of principal part, we confirm these interest relatives of enterprise, which are seen in Figure 1. The so-called interest relative means any relative influenced by organizational decisions and activities in the exterior environment of the organization. These relative groups are closely linked with the organization, or the organizational activity would strongly influence them (Stephen, 2003, p.78).

The key for enterprise to strengthen competitiveness relies on such aspects as how to select the appropriate cooperant object in its interest relatives such as same industrial competitors, research institutions, financial institutions, governments and agents and suppliers (Chen, 2002, p.14-16), how to select the appropriate coupling strategy on the ligament bases of social relations and information network, how to select the appropriate network cooperation 
innovation mode based on effectively utilizing interior and exterior innovation resources.

\section{Formation of enterprise competitive potential}

The competitive potential of enterprise is the base of enterprise competitiveness, and only the enterprise with certain potentials can form enterprise competitiveness and actualize competitive predominance through available approaches. The acquirement of enterprise competitive potential is realized through three processes including industrial cluster, embeddedness, and netting, which are seen in Figure 2.

\subsection{Industrial cluster makes enterprise obtain the predominance of space competition.}

The industrial cluster is the aggregation composed by a group of relative enterprises in a same geographical region (Chenery, 1996, p.95). The industrial cluster can strengthen the function assembling space of the region, and create conditions to actualize regional scale economy and implement large scale customized production. The industrial cluster can improve exterior scale economy and exterior scope economy of single enterprise, and reduce its production costs and form price predominance. The industrial cluster also can establish mutually trusting economic network under same industrial background, can promote that transnational groups spread and diffuse knowledge and technology to local medium and small enterprises, and accordingly bring the space competitive predominance for the enterprises in the region to actualize the innovation of products.

\subsection{Embeddedness makes enterprise actualize localization.}

The character of embeddedness roots in economic sociology, which means that economic activities are deeply embedded in the social relation. Those enterprises in the cluster not only possess the geographical predominance, but they have strong local relations which are presented not only in economy, but also in many aspects such as politics, society, and culture. Mutual social cultural environment will produce trust and understanding, and mutual cooperation, mutual trust and satisfaction will become the most valuable resources in the region. Embeddedness is the important process in the development of network. Eenterprises from outside, especially those transnational enterprises take the relation localization as their core, take the product localization as their support, depend the market localization to win regional customers, utilize employee and research localization to foster local human resource (Zhou, 2003, p.34-35), and this series of embeddedness processes make enterprises from outside and local enterprises form fixed industrial chain and continually implement the adjustment of industrial structure, contribute for the development of local industry, and accordingly drive the increase of enterprise competitiveness in the region.

\subsection{The development of network improves the total enhancement of regional competitiveness.}

The network relation is divided into normal relation and informal relation. The normal relation presents the relation formed through various formal contracts among various activity principle parts. The informal network relation presents the relative stable relation formed in non-contractual and long-term communicational process. The government specially supports the enterprise which has development future for the local region. The financial institution notices and participates in the research works of new product through offering loans with low interests to local enterprises. Academies and scientific research institutions offer persons with ability and intelligent supports. Suppliers and agents compel enterprises in the region expedite technical update, improve management methods and enhance the production level of enterprises through putting forward technical requirements and product performance indexes to regional enterprises. All these measures make enterprises in the center status of network benefit more.

\section{Strengthening of enterprise competitiveness}

The increase of competitive strength of certain industry in the region happens in the flexible associations among every enterprise with other interest relatives, and enterprises can realize the increase of competitive strength through fully utilizing rich resources in the network.

\subsection{Competing with competitors and actualizing the heterogeneity of enterprise}

Because information among enterprises in the network are symmetrical, so trades among enterprises possess durative, which decides that the competitions among enterprises are infinite repeated games, and enterprises generally dare not breach contracts, so good cooperation can be implemented favorably (Liu, 2006, p.73-78).

Cooperation is the good premise to implement competition. Enterprises should take competition as the impetus of continual improvement and innovation, and to avoid being annexed or eliminated, they must continually enhance the level of production technology, improve the management mode, reduce various production fees, and advance their own competitive ability. As viewed from a short term, the competitiveness of enterprise comes from the price and performance of present product. As viewed from a long term, the competitiveness of enterprise comes from lower costs comparing with competitors and the ability to rapidly foster product, i.e. the core ability, which requires enterprises in the network to gradually form their own core ability and actualize the heterogeneity in the long-term cooperation and competition. 


\subsection{Depending on the support and service of the government, enhancing the innovation ability of enterprise}

The principal parts of interest in the network all enjoy rights brought by the network when they perform their own obligations. When enterprises bring revenues for regional government, the government also actively influences the innovation of enterprises. Though the government in the region can not directly create new knowledge, technology and product, it can offer a good environment for the transmission of interior knowledge and information in the network, offer a sort of mechanism to promote affiliations of enterprises in the network with other principal parts of activity, enhance the cooperant efficiency among enterprises, compensate the deficiency of market forces, and drive the development of enterprises. For example, the government can inspirit the development and innovation of science and technology, ensure the favorable currency of technical innovative factors through the establishment of leading policies. Those main enterprises in the network can fully utilize various policies and measures implemented by the government, which aims to improve the development of enterprise and enhance the ability of innovation.

\subsection{Utilizing capital market and forming the financial support to enterprise}

Financial institutions in the network generally include local state-owned banks, regional merchant banks, various funs, institutions of loan capital, risk investment institutions. At present, the capitals needed by enterprises to implement innovation are more and more, and the capital deficiency is the main bottlenecks to limit enterprises (especially those medium and small enterprises) to develop new products. Under this situation, enterprises in the network can establish the cooperation with the capital market to compensate their own capital deficiency, and they can get loan from financial institutions, and they can also implement financing by bonds, stocks or issuing international stocks and bonds in the international capital market, and theses diversifications of financing approach will offer enough capital supports for enterprises.

\subsection{Strengthening the cooperation with scientific research academies and acquiring technical resources}

The cooperation of enterprise with scientific research institutions can better acquire valuable knowledge, information and technology, and enhance the learning ability and the innovation ability. This sort of cooperation is the typical cooperation of production, learning and research, and the process of cooperation is the process of knowledge transformation (He, 2006, p.63-68). To high technical industry, this cooperation has strong complementarity, especially under the situation that many enterprises only possess low technical innovation ability, and the cooperation with scientific research academies is the important approach to acquire technical resource. This sort of cooperation can be implemented not only by the commercial channels such as technical consultation, technical franchise, and derived enterprises which can transfer college techniques, but also by non-commercial channels. For example, the scientific research academies offer scientists and engineers with high quality for the enterprise, and the scientific research academies implement inventions through scientific theses and patents, and both parties' personnel exchanges and communication without day.

\subsection{Establishing good relations with suppliers and customers, reducing costs and fostering customer group}

The relations of enterprise with suppliers, customers is mainly embodied in the relation of upper and lower parts on the industrial chain, because for any enterprise, enterprise is not only the supplier, but also the customers, and the relation between supplier or customers is generally embodied in the trading relation, that is to say, enterprise exchanges raw materials or components with suppliers, and trades products and services with customers. In the network, the relation between supplier and customer comes from the support of three spaces including economic space, social space, and geographical space. In the process to promote enterprise innovation and development and regional economic development, these three spaces exert functions at the same time, and the supplier and the customer not only can trade through market rule in the market, but also establish long-term cooperation after many times trades (Gai, 2002, p.47-118). The enterprise and supplier can utilize geographical predominance, fully exert the functions of timely production technique and transportation system, reduce production costs each other. Except for reducing costs of raw materials and components, suppliers can actively participate in the total process from product design to product making, and enterprises can enhance suppliers' enthusiasm to implement product innovation and technical innovation through adding orders. In the day of buyer's market, competition is not only the competition of price, but the competition of quality and diversity. Therefore, enterprises should increase the communication with customers, know and fulfill customers' real demands, and foster customers' loyalty to enterprises.

\section{Continual renovation of enterprise competitiveness}

The innovation of enterprise should take employees' knowledge absorption, intercommunion and sharing as the base. The organizational learning is the necessary condition for the innovation of enterprise, and the result of enterprise innovation is embodied in the recombination of original knowledge and the appearance of new knowledge, i.e. the increase and accumulation of enterprise knowledge. The entrepreneur's innovative spirit is the essential impetus to organize leaning and knowledge accumulation for the enterprise, and the essential aim of learning and absorption, intercommunion and sharing of enterprise knowledge is to support the enterprise innovation based on entrepreneur's 
spirit, and foster sustainable competitive predominance (Jin, 2003).

To enterprises in the network, the developmental policies of enterprise can be acquired from policy perferrence of the government, and the technique to develop new product can be introduced from scientific research institutions and colleges, and capitals in the process of product development and production can be acquired from many financing channels in financial institutions, and the long-term development of enterprise needs brainy entrepreneur's layout with employees together. The entrepreneur's innovative decisions should be established on the forecast of grasp and future development of market opportunity, and new competitive predominance source can be realized. At the same time, the entrepreneur's innovative decision also can destroy present competitive predominance. Just because of the existence of theses entrepreneurs' innovative decisions, present sources of innovative predominance are continually destroyed and new innovative predominance continually occurs, and the enterprise competitiveness is updated continually. For entrepreneurs, they should possess not only innovative abilities, but also destroyable ability to original things. For employees, enterprise can strengthen employees' loyalty through good enterprise culture, establish perfect training system to train various talents for the enterprise, and establish effective stimulation system to exert employees' enthusiasm to large extents. Enterprises also should establish the platform on which employees can absorb, exchange and share knowledge to actualize continual innovation of enterprise.

\section{References}

Chenery H. (1996). Comparative Research on the Industrialization and Economic Increase. Shanghai: Shanghai Joint Publishing Company. p.95.

Chen, Xinyue, Yang, Deli \& Dong, Yizhe. (2002). The Choice of Enterprise Innovation Network Model. Scientific Management Research. No.20 (6). p.14-16.

Gai, Wenqi. (2002). Innovation Network: New Thinking of Regional Economy. Beijing: Beijing University Press. p.47-118.

He, Yaqiong, Ge, Zhongfeng \& Sujun. (2006). A Research on Studying Mechanism among Organizations in the Network of Regional Innovation. Academic Exchange. No.143 (2). p.63-68.

Jinbei. (2003). Economics of Competitiveness. Guangzhou: Guangdong Economy Press. No.4.

Lei, Ruqiao, Chen, Jixiang \& Liuqin. (2004). Research on the Interaction Mechanism of Cluster's Networks. Science of Science and Management of S. \& T.. No.12. p.60-63.

Liu, Aixiong, Zhang, Gaoliang \& Zhubin. (2006). Analysis of the Origin of Industrial Clusters Competitiveness. Science of Science and Management of S. \& T.. No.1. p.73-78.

Stephen P. Robbins, Mary Coulter. (2003). Management. Beijing: China Renmin University Press. p.78.

Zhou, Lianxi. (2003). The Countermeasures of Multinational Corporation in Localilzation Strategy and China Local Enterprises. Journal of Business Economics. No.9. p.34-35.

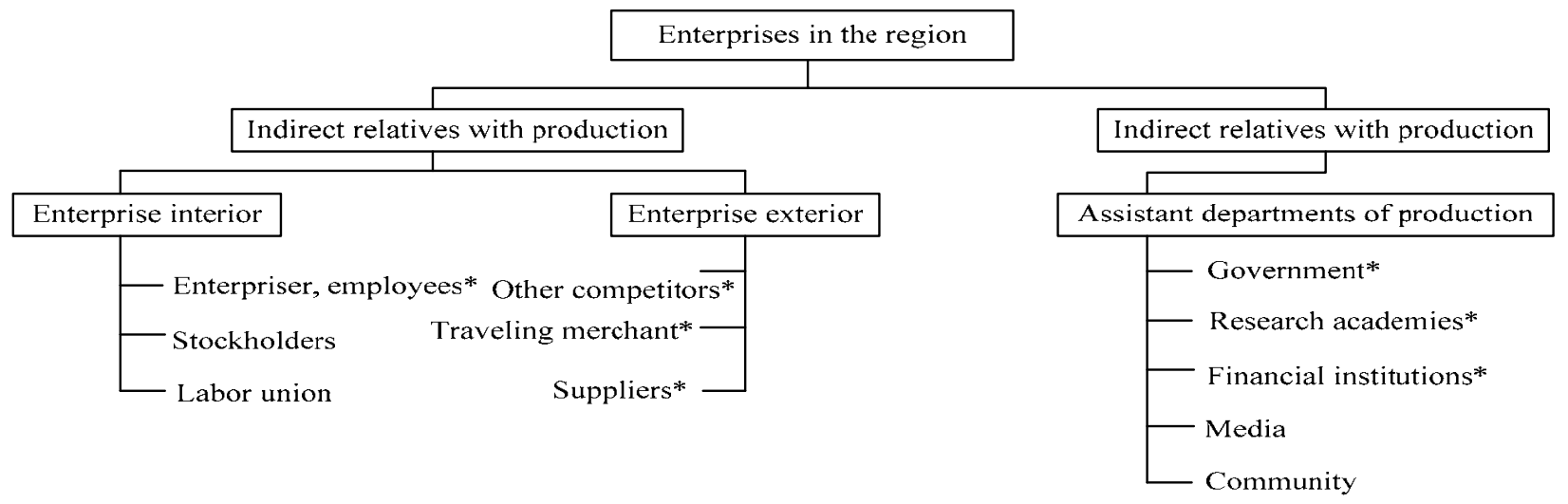

Figure 1. Interest Relatives of Enterprise in the Region

Note: The item added "**" is the important interest relative in Figure 1.

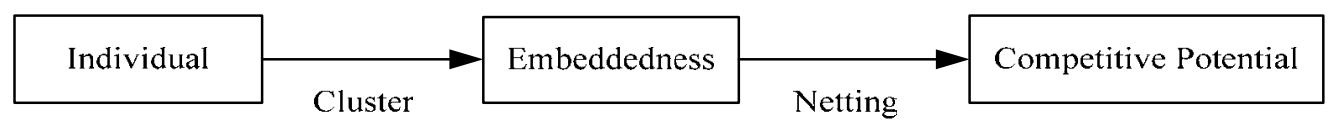

Figure 2. Acquirement Process of Enterprise Competitive Potential 